\title{
Neurotoxic Zanthoxylum chalybeum root constituents invoke mosquito larval growth retardation through ecdysteroidogenic CYP450s transcriptional perturbations
}

Jackson Mbithi Muema ( $\nabla$ jackson_mbithi@yahoo.com )

Jomo Kenyatta University of Agriculture and Technology

Joel L. Bargul

Jomo Kenyatta University of Agriculture and Technology

James M. Mutunga

US Army Medical Research Directorate-Africa

Meshack A. Obonyo

Egerton University

George 0. Asudi

Kenyatta University

Sospeter N. Njeru

Kisii University College Faculty of Health Sciences

\section{Research}

Keywords: Mosquitoes, Neurotoxicity, Zanthoxylum chalybeum, Natural products, Growth retardation, Ecdysteroidogenic CYP450s, Vector control

Posted Date: August 3rd, 2020

DOI: https://doi.org/10.21203/rs.3.rs-49975/v1

License: (a) (i) This work is licensed under a Creative Commons Attribution 4.0 International License. Read Full License

Version of Record: A version of this preprint was published at Pesticide Biochemistry and Physiology on June 1st, 2021. See the published version at https://doi.org/10.1016/j.pestbp.2021.104912. 


\section{Abstract}

Background: Intracellular effects exerted by phytochemicals eliciting insect growth-reducing responses during vector control intervention remain largely underexplored. We studied the effects of Zanthoxylum chalybeum Engl. (Rutaceae) (ZCE) root derivatives against malaria (Anopheles gambiae) and arbovirus vector (Aedes aegypti) larvae to decipher possible molecular targets.

Results: We report dose-dependent biphasic effects on larval response, with transient exposure to ZCE and its bioactive fraction (ZCFr.5) inhibiting acetylcholinesterase (AChE) activity, inducing larval lethality and growth retardation at sublethal doses. Half-maximal lethal concentrations $\left(\mathrm{LC}_{50}\right)$ for ZCE and ZCFr.5 against An. gambiae and Ae. aegypti larvae after 24-h exposure were 9.00 ppm, 12.26 ppm, and 1.58 ppm, 3.21 ppm, respectively. Inhibition of AChE was potentially linked to larval toxicity afforded by 2tridecanone, palmitic acid (hexadecanoic acid), linoleic acid ((Z,Z)-9,12-octadecadienoic acid), sesamin, $\beta$-caryophyllene among other compounds identified in the bioactive fraction. In addition, the phenotypic larval retardation induced by ZCE root constituents were exerted through transcriptional modulation of ecdysteroidogenic CYP450 genes.

Conclusion: Collectively, these findings provide an explorative avenue for developing potential mosquito control agents from $Z$. chalybeum root constituents.

\section{Background}

Renewed interests in search of environmentally friendly alternative insecticides have lately led to the gradual substitution of chemical-based insecticides in global markets. However, as much as the public demand for biocides over their synthetic counterparts continues to increase and considerable appreciation of plant-derived bioactive compounds in pest control [1-3], the mechanistic effects mediated by these insecticidal agents at a molecular level as well as their target proteins remain largely elusive. Only studies focusing on phytophagous insects highlight structurally-based concerted cellular interference of vital physiological processes by growth-reducing plant compounds [4]. Conversely, detailed molecular toxicity studies to demystify the mechanisms of action of various mosquitocidal agents are few. In a recent study, tea proanthocyanidins interfered with mosquito larval growth and reproduction fitness by physiologically disrupting the juvenile hormone biosynthetic pathway [5]. Using a yeast two-hybrid reporter system, Lee et al. showed that juvenile hormone mimics derived from Lindera erythrocarpa (Lauraceae) and Solidago serotina (Asteraceae) effectively antagonized mosquito juvenile hormone receptor, methoprene-tolerant (Met); killing mosquito larvae and retarding follicle development in the ovaries [6]. Larvicidal activity of annonaceous acetogenin (squamocin) was associated with multitarget midgut gene effects in Aedes aegypti larvae [7]. In other studies, terpenes and terpenoids, polyphenols, alkaloids, and prenylpropanoid compounds were found to target the larval neurotransmission process, inducing sudden neuronal toxicity and death [8]. 
The post-embryonic insect molting, developmental timing, and morphological remodelling events controlled by periodical ecdysteroid pulses are under neural regulatory and nutritional inputs $[9,10]$. These metamorphosis behavioral changes are orchestrated by biosynthesis and release of growth hormones upon decoding sensory environmental cues from insulin/insulin-like signaling and target of rapamycin (IIS/TOR) pathway. Ecdysteroids synthesized through sequential enzymatic oxidation of dietary cholesterol in the prothoracic glands are released into the hemolymph where they are activated into 20hydroxyecdysone (20E) [11]. Major advancements have been made to understand ecdysone functions in insect physiology. For instance, through comprehensive molecular analyses in model insects (e.g. Drosophila melanogaster) and other related species, it is evident that ecdysteroidogenic pathway is transcriptionally regulated by Halloween genes that encode CYP450 enzymes; Neverland, non-molting glossy (nmg), CYP307A1/spook, CYP307A2/spookier, CYP306A1/phantom, CYP302A1/disembodied, CYP315A1/shadow and CYP314A1/shade, and a number of nuclear transcription factors $[9,12,13]$. Following ecdysone activation to $20 \mathrm{E}$ within the peripheral tissues by shade, it binds to the ecdysone receptor (EcR) forming a heterodimeric complex with Ultraspiracle (USP). The resultant trimeric complex 20E/EcR/USP binds ecdysone response elements (EcREs) activating transcriptional expression of 20Einducible genes; $E 74, E 75 A, H R 3$, Broad, $\beta F t z-F 1$ and other downstream proteins involved in metamorphosis and morphogenesis [14]. Biosynthesis and release of ecdysteroids from neurosecretory cells in metamorphosing juvenile insects could apparently be halted under modulatory chemical environment, underscoring the anti-ecdysteroid-inducing effects of certain xenobiotic stressors.

In multicellular organisms, neuronal coordination network of nerve circuits is regulated by a serine hydrolase acetylcholinesterase (AChE; E.C 3.1.1.7), which rapidly terminates synaptic signals by hydrolyzing the neurotransmitter, acetylcholine (ACh), into inactive derivatives [15]. Besides this primary function, the implication of AChE in atypical noncholinergic roles [16] including the regulation of insect growth and development is characterized. Exemplified by this important functional role in cellular development and survival, AChE continues to be explored in biotechnological and chemical-based control of crop pests and insect vectors [17-19]. As a biochemical target of organophosphates and carbamates, through phosphorylation or carbamoylation of a conserved serine residue (Ser200), AChE delineates a classical pest control chokepoint, despite its vulnerability to point mutations associated with decreased insecticide sensitivity. Various RNA interference (RNA $i$ ) studies targeting Ace of diverse insects including Helioverpa armigera (Noctuidae), Chilo suppresalis (Crambidae), Plutella xylostella (Plutellidae), Tribolium castenum (Tenebrionidae), Bemisia tabaci (Aleyrodidae), fall armyworm Spodoptera frugiperda (Noctuidae), and Bombyx mori (Bombycidae) have reported adverse effects on larval growth and survival, delayed pupation and adult emergence, reduced motor control and female reproductive viability [20-26], implicating a significant role of AChE in insect growth physiology. Most likely, the mentioned findings could postulate a direct involvement of $\mathrm{AChE}$ in the regulation of insect hormonal activities. In fact, previous studies in metamorphosing brain of Tenebrio molitor, and cell lines of Chironomus tentans, Ae. aegypti, S. frugiperda, and D. melanogaster have demonstrated relationship between AChE activity and its regulation by ecdysteroid hormone levels and vice versa [27-30]. Studies using $D$. melanogaster and Manduca sexta as models have further provided significant insights into how insect larval-pupal 
transition behavior through ecdysis and tissue differentiation is driven by motoneuron networks controlled by ecdysteroid hormone and EcR activity [31-33]. Based on these interactions and interdependent co-regulatory mechanisms during growth, transcriptional dysregulation of either AChE or ecdysteroid genes by chemical intervention, RNAiand/or genetic ablation could adversely affect hormone-regulated insect growth by inducing toxicity and retardation phenotypes of inter-instar and larval-pupal transitions. In spite of this knowledge, the underlying molecular mechanisms responsible for the growth retardation effects exerted by inhibitory influences on insect AChE remain unclear.

Underscoring the public health importance of mosquitoes in the transmission of life-threatening diseases, particularly malaria and arboviral infections, vector control aiming at area-wide suppression of adult populations are reconsidering targeting the juvenile larval stages [34]. This is largely due to the evergrowing concerns of insecticide resistance and other consequential behavioral effects associated with intensified adult vector interventions. Due to cost and environmental concerns associated with synthetic mosquito larvicides, community-based vector control interventions have shown great interest in the application of naturally occurring botanicals for mosquito control around human dwellings [35-38]. In that regard, intensified laboratory screening of plant derivatives have reported a number of effective larvicides, among them derived from Zanthoxylum plant species [39-43]. While several plant-derived AChE antagonists are potent insecticides, the knowledge of how they functionally affect insect larval development is underexplored. No existing studies of $Z$. chalybeum (knobwood) bioactivity against mosquitoes and therefore the current study reports the effects of its root chemical constituents on developing An. gambiae and Ae. aegypti juveniles. We demonstrate that dysregulation of mosquito larval nervous coordination upon exposure to ZCE root extract and its bioactive fraction (ZCFr.5) retards larvalpupal transitions through transcriptional perturbation of ecdysteroidogenic CYP450 regulatory genes and effector transcription factors.

\section{Results}

\section{ZCE and its bioactive fraction are neurotoxic and retards mosquito larval development in a dose- dependent manner}

Previous studies have demonstrated inhibition of An. gambiae, Ae. aegypti, Culex pipiens, and Ae. albopictus mosquito larval development by Zanthoxylum plant extracts [39-43]. Currently, we report that mosquito larvae exposed transiently to ZCE at $15-25 \mathrm{ppm}$ were immobilized and less active within the first 20 min for both An. gambiae and Ae. aegypti (data not shown). This exposure elicited $60-100 \%$ larval mortalities at $\mathrm{LC}_{50} 9.00 \mathrm{ppm}(95 \% \mathrm{Cl} 8.62-21.50)$ and $\mathrm{LC}_{50} 12.26 \mathrm{ppm}(95 \% \mathrm{Cl}$ 9.04-19.80) against $A n$. gambiae and Ae. aegypti, respectively, within 24-h post-treatment (Table 1, Fig. 1). When compared to the negative controls that achieved $100 \%$ survival, ZCE significantly reduced larval survival rates ( $A n$. gambiae, $\mathrm{F}_{(5,24)}=105.5, p<0.001 ;$ Ae. aegypti, $\left.\mathrm{F}_{(5,24)}=314.4, p<0.001\right)$ but slightly higher doses were required to match the activity of neem oil that was included as positive control. However, the variation in susceptibility to ZCE toxicity was insignificant $\left(\mathrm{F}_{(1,48)}=0.836, p=0.365\right)$. Fractionation of ZCE yielded a bioactive hexane-soluble fraction (ZCFr.5) with similar activity to ZCE but at lower doses of LC 501.58 
ppm (95\% Cl 0.62-2.87) and 3.21 ppm (95\% Cl 2.99-3.83) against An. gambiae and Ae. aegypti, respectively (Table 1, Fig. 1). Other solvent fractions yielded no activity (Supplementary Table S1).

Table 1. Toxicity of ZCE extracts on An. gambiae and Ae. aegypti larvae 24-h post exposure.

\begin{tabular}{|c|c|c|c|c|c|}
\hline \multirow[t]{2}{*}{ Treatments } & \multirow[t]{2}{*}{$\begin{array}{l}\text { Concentration } \\
\text { (ppm) }\end{array}$} & \multicolumn{2}{|c|}{$\begin{array}{l}\text { Larval mortality } \\
\text { (\% mean } \pm \text { S.D) }\end{array}$} & \multicolumn{2}{|c|}{$\mathrm{LC}_{50}(95 \% \mathrm{CI})$} \\
\hline & & $\begin{array}{l}\text { An. } \\
\text { gambiae }\end{array}$ & $\begin{array}{l}\text { Ae. } \\
\text { aegypti }\end{array}$ & An. gambiae & Ae. Aegypti \\
\hline \multirow[t]{5}{*}{$\begin{array}{l}\text { MeOH extract } \\
\text { (ZCE) }\end{array}$} & 25 & $\begin{array}{l}100 \pm \\
0.00^{\mathrm{a}}\end{array}$ & $\begin{array}{l}100 \pm \\
0.00^{\mathrm{a}}\end{array}$ & $9.00(8.62-21.502)$ & $\begin{array}{l}12.26(9.04- \\
19.799)\end{array}$ \\
\hline & 20 & $94 \pm 1.64^{\ddagger}$ & $79 \pm$ & & \\
\hline & 15 & $78 \pm 3.36^{\ddagger}$ & $62 \pm$ & & \\
\hline & 10 & $66 \pm 1.82^{\ddagger}$ & $37 \pm$ & & \\
\hline & 5 & $38 \pm 3.36^{a}$ & $\begin{array}{c}2 \pm \\
0.894^{\mathrm{a}}\end{array}$ & & \\
\hline \multirow[t]{5}{*}{$\begin{array}{l}\text { Hexane soluble fraction } \\
\text { (ZCFr.5) }\end{array}$} & 10 & $\begin{array}{l}100 \pm \\
0.00^{\mathrm{a}}\end{array}$ & $\begin{array}{l}100 \pm \\
0.00^{\ddagger}\end{array}$ & $1.58(0.62-2.87)$ & $\begin{array}{l}3.21(2.99- \\
3.83)\end{array}$ \\
\hline & 7.5 & $94 \pm 2.28^{\mathrm{a}}$ & $\begin{array}{c}87 \pm \\
0.447^{\ddagger}\end{array}$ & & \\
\hline & 5 & $90 \pm 1.12^{\mathrm{a}}$ & $\begin{array}{c}75 \pm \\
2.387^{a}\end{array}$ & & \\
\hline & 2.5 & $78 \pm 0.98^{a}$ & $\begin{array}{c}24 \pm \\
3.162^{\mathrm{a}}\end{array}$ & & \\
\hline & 1 & $25 \pm 2.23^{\mathrm{a}}$ & $10 \pm$ & & \\
\hline Neem oil (positive control) & 3.8 & $98 \pm 1.59$ & $\begin{array}{c}100 \pm \\
0.00\end{array}$ & & \\
\hline
\end{tabular}

Late third instar mosquito larvae of An. gambiae and Ae. aegypti were exposed to various doses of ZCE (5-25 ppm) and its active fraction (1-10 ppm) and mortalities in each setup recorded for 24-h against the controls. Mosquito population size $(\mathrm{N})$ per treatment dose per replicate was 125 larvae $(n=2$ biological replicates). Mean values followed by a double dagger ( $\ddagger)$ are not significantly different. Values followed by a superscript letter are significantly different $(p<0.05$, One-way ANOVA - Tukey-Kramer's multiple comparison test). ppm denotes parts per million, S.D - standard deviation, $\mathrm{Cl}$ - confidence interval, $\mathrm{LC}_{50}$ - lethal concentration on $50 \%$ of test population.

We also evaluated the residual effect of long term exposure on developmental growth progression. Upon treatment with sublethal dosage of either the ZCE ( or hexane-soluble bioactive fraction (ZCFr.5), the larval transition to pupal stages was abnormally extended (averagely $3.75 \pm 0.1732$ days, Table 2 ) inducing retardant phenotypes (ZCE: An. gambiaet $=15.963, p=0.0004243 ;$ Ae. aegyptit $=23.883, p=$ 0.0004457; ZCFr.5: An. gambiaet $=30.311, p=0.001087$, Ae. aegyptit $=7.0162, p=0.01272$ ). Further, unlike the controls that achieved $>82 \%$ pupation (Table 2 ), pupation rate for the treated cohorts was significantly affected with many dying at larval state (ZCE: An. gambiaet $=-18.826, p=0.0007721 ;$ Ae. 
aegyptit $=-19.078, p<0.0001 ;$ ZCFr.5: An. gambiaet $=-14.233, p=0.0001549$, Ae. aegyptit $=-31.787, p$ $=0.0006135)$. Overall, species-specific perturbations were noted, with more treatment effects in $A n$. gambiae than Ae. aegypti (ZCE, $\mathrm{t}=-11.539, p=0.0005719 ; \mathrm{ZCFr} .5, \mathrm{t}=-6.3535, p=0.02296)$.

Table 2. Developmental duration of mosquito larvae treated with sublethal doses of $Z$. chalybeum extracts

\begin{tabular}{lll}
\hline Treatment & Pupation time (days) & Pupation rate (\%) \\
\hline An. gambiae & & \\
\hline Non-treated control & $5.30 \pm 0.17^{\mathrm{a}}$ & $85.33 \pm 3.10^{\mathrm{a}}$ \\
$0.01 \%$ ethanol control & $5.60 \pm 0.20^{\mathrm{a}}$ & $82.61 \pm 3.89^{\mathrm{a}}$ \\
ZCE & $9.10 \pm 0.00^{\mathrm{b}}$ & $37.22 \pm 1.51^{\mathrm{b}}$ \\
ZCFr.5 & $9.40 \pm 0.36^{\mathrm{b}}$ & $34.73 \pm 1.72^{\mathrm{b}}$ \\
\hline Ae. aegypti & \\
\hline Non-treated control & $4.80 \pm 0.35^{\mathrm{c}}$ & $89.40 \pm 2.71^{\mathrm{c}}$ \\
0.01\% ethanol control & $5.00 \pm 0.26^{\mathrm{C}}$ & $86.15 \pm 1.90^{\mathrm{c}}$ \\
ZCE & $8.90 \pm 0.10^{\mathrm{d}}$ & $54.65 \pm 2.14^{\mathrm{d}}$ \\
ZCFr.5 & $8.80 \pm 0.90^{\mathrm{d}}$ & $50.55 \pm 0.39^{\mathrm{d}}$ \\
\hline
\end{tabular}

${ }^{\ddagger}$ Time period recorded from early L3 instar until pupal transformation for three replicates. Values presented as means \pm standard deviation (S.D). Mean values followed by similar superscript letters are not significantly different (One-way ANOVA - Tukey-Kramer's multiple comparison test, $p<0.05$ ). Sublethal dosages used: ZCE: 8 ppm, 10 ppm; ZCFr.5: 1.0 ppm, 3 ppm for An. gambiae, and Ae. aegypti, respectively

\section{Phytochemical analysis identified an abundance of insect growth reducing compounds}

To identify the chemical constituents present in the bioactive hexane-soluble fraction (ZCFr.5), the yellow brown oily sample was subjected to a gas chromatography-mass spectrometer (GC-MS) analyzer. From a total of 67 components (Supplementary Table S2), the GC-MS analyzer detected among other compounds the presence and abundance of previously reported insect growth-reducing agents[42][44], corresponding to 2-tridecanone (1) (Rt 18.2267), hexadecanoic acid (2) (Rt 23.3864), (Z,Z)-9,12octadecadienoic acid (linoleic acid) (3) (Rt 25.0829), sesamin (1,3-Benzodioxole,5,5'-(tetrahydro-1H,3Hfuro[3,4-c]furan-1,4-diyl)bis-,[1S-(1.alpha.,3a.alpha.,4.beta.,6a.alpha.)]-) (4) (Rt 34.3786) and $\beta$ caryophyllene (5) (Rt 38.38)(Fig. 2A, 2C). Proportionately, the compounds 1, 2, 3, 4, and 5 contributed to $10.82 \%, 7.71 \%, 11.14 \%, 11.43 \%$, and $10.38 \%$, respectively, representing $51.48 \%$ of the total active biomass (Fig. 2B).

\section{Perturbed acetylcholinesterase (AChE) activity linked to larval lethality}

Transient exposure of mosquito larvae to ZCE and its bioactive fraction for $<5 \mathrm{~h}$ exhibited no obvious morphological aberrations but drastically reduced larval swimming behavior, induced muscle paralysis and immobilization leading to death. These observations are closely linked to neuromuscular toxicity effects reported by Tomé et al.[45]. To ascertain whether the observed acute toxicity on mosquito larvae 
was as a result of suppressive effects of ZCE and its bioactive fraction on AChE, we performed the biochemical colorimetric Ellman's enzymatic assay and RT-qPCR gene expression analysis. Due to the low amount of ZCFr.5, we only assayed ZCE for larval AChE activity inhibition. ZCE exhibited dosedependent AChE inhibitory effect in mosquito larvae (Fig. 3B), attaining $\mathrm{IC}_{50} 136.0 \mu \mathrm{g} / \mathrm{mL}(95 \% \mathrm{Cl} 111.3$ 547.3) and $277.5 \mu \mathrm{g} / \mathrm{mL}(95 \% \mathrm{Cl}$ 47.4-293.4) for Ae. aegypti and An. gambiae, respectively. The AChE inhibition achieved by ZCE was preferably 1.4-2.73 fold higher in Ae. aegypti (44.19-81\%) than An. gambiae (16.11-59.59\%). Irrespective of ZCE dosage, the toxicity susceptibility of AChE significantly varied between Ae. aegypti and An. gambiae (Welch two-sample t-test, $p<0.001$ ), highlighting a speciesspecific response. Relative to propoxur, a specific carbamate-based irreversible $A C h E$ inhibitor, the mean ZCE activity varied significantly between the species (An. gambiae; $\mathrm{t}$-test, $\mathrm{t}=-8.4174, \mathrm{df}=4, p=0.001055$; Ae. aegypti, $\mathrm{t}=-2.9963, \mathrm{df}=4, p=0.03648)$. Agreeably, the larval treatment with ZCFr.5 was associated with 0.0764 and 0.017-fold Ace transcriptional changes in Ae. aegypti and An. gambiae, respectively (Fig. $3 \mathrm{~A}$ ), but these expressions were not significantly different from each other (t-test $=2.4406, \mathrm{df}=4, p=$ 0.066). Meaningful and significant $(p>0.05)$ negative correlation coefficients between the mean $\mathrm{LC}_{50}$ and AChE inhibition values of ZCE were obtained, but not varied between the two mosquito species (Supplementary Table S3).

\section{ZCFr.5 modulates mosquito larval ecdysteroid biosynthetic and transcriptional regulatory genes}

Lignan-based prenylpropanoid and 2-tridecanone compounds are believed to inhibit ecdysteroids and their biosynthetic-dependent cytochrome P450 activities[44][46], interfering with insect growth. As expected, the sesamin-rich ZCE root fraction altered the transcriptional expression of ecdysteroid biosynthetic Halloween and regulatory genes (Fig. 4). Notably, the larvicide treatment significantly downregulated the expression of larval 'black box' cytochrome P450 spook (Cyp307a 1), $\beta F t z-F 1$, disembodied (Cyp302a1), and ecdysteroid receptor (EcR) genes. We further noted that, with an exception of Cyp302a1 in Ae. aegypti, the gene expressions of Cyp314a1, Cyp306a1, and dHAT were not significant from each other (t-test, $p>0.05$; Fig. 4A-B), but remarkably modulated relative to the controls. Intriguingly, while juvenile hormone $(\mathrm{JH})$ expression levels decrease during the last larval instar to allow 20E-induced transformation into pupal stages, we established that the expression of $\mathrm{JH}$ biosynthetic rate-limiting enzyme, $\mathrm{JH}$ acid $O$-methyltransferase (JHAMT), in ZCFr.5-treated larvae remained relatively higher compared to that of controls (Fig. 4C-D). This finding could suggest low levels of circulating hemolymph $20 \mathrm{E}$ to suppress $\mathrm{JH}$ and further underscoring the observed larval growth retardations and precocious pupations. These findings confirmed that indeed the larval treatment that targeted AChE activity also perturbed ecdysteroidogenic pathway associated genes delaying larval-pupal transitions and inducing retardant phenotypes.

\section{Discussion}

The impact of plant-derived insecticidal compounds on insect tissues elicits pleiotropic growth effects for which a number of insecticides specifically targeting neuromuscular activity have overlooked at the molecular level. Herein we investigated the bioactivity of $Z$. chalybeum root constituents against $A n$. 
gambiae and Ae. aegypti larvae with a keen focus on elucidating the possible downstream toxicity effects. Our findings demonstrate that the fast-acting ZCE constituents elicit larvicidal activities in a dosedependent fashion by targeting the neuromuscular actions regulated by AChE and further invoking larval retardation at sublethal doses through disrupted ecdysteroidogenesis. While similar observations have previously been reported using RNAi assays in other insects [20-26], we report for the first time the effect of ZCE root constituents to dysregulate neural-linked ecdysteroidogenesis in mosquito larvae, inducing retardants that fail or exhibit delayed pupation.

Zanthoxylum plant species have been reported to possess insecticidal, repellent and larvicidal activities exerted by compounds mostly concentrated within the hexane-soluble portions [40-42,47-54]. Similarly, Z. chalybeum larvicidal activity reported in this study was more pronounced in hexane-soluble fraction suggesting that the lipophilicity parameter was key in mediating the observed acute toxicity effects. Compared to their reported bioactivities exerted at relatively higher $\mathrm{LC}_{50}$ doses, ZCE and its active fraction (ZCFr.5) provoked larval toxicities at low $\mathrm{LC}_{50}$ doses (1.58-12.26 ppm) against An. gambiae and Ae. aegypti, possibly due to species-specific distribution of the secondary metabolites. While different compounds from the stem barks, seeds, and leaves were reported to differentially interfere with mosquito survival, we detected for the first time the presence and abundance of sesamin, 2-tridecanone, $(Z, Z)-9,12$ octadecadienoic acid (linoleic acid), hexadecanoic acid (palmitic acid), and $\beta$-caryophyllene in $Z$. chalybeum root extract that have previously been reported to exhibit growth reducing effects in insects. For instance, the phenylpropanoid lignan, sesamin, has been reported in Zanthoxylum stem barks to elicit moderate larvicidal activity ( $\mathrm{LC}_{50}>150 \mu \mathrm{g} / \mathrm{mL}$ ) [41] but relatively with similar bioactivity to ZCE against Ae. aegypti at $14.28 \mathrm{mg} / \mathrm{L}$ [42]. Further, an aliphatic methyl ketone (2-tridecanone) exhibited repellent effects against both Amblyomma americanum (Ixodidae) and Dermacentor variabilis (Ixodidae) ticks, and An. gambiae [55,56]. Strikingly, this carbonyl compound (2-tridecanone) retards insect growth by down-regulating Halloween CYP450 genes [46], a feature corroborated in the current study. In addition, the ubiquitous caryophyllene and fatty acids, such as linoleic acid and palmitic acid, have previously exhibited larval toxicity mediated through AChE inhibition [57]. Ingestion and/or cuticular penetration of this blend of compounds presumably interacted with larval tissues, thus incapacitating mosquito larvae during 24-h of treatment. Considering the larvicidal activity of ZCE compounds appeared to be associated with muscle paralysis manifesting in uncoordinated motility, inhibition against AChE appeared to be as a result of the lipophilic nature of these compounds that transverse cell membranes to their target site, possibly increasing ACh levels and overstimulating neuromuscular action akin organophosphates. Our findings agree with those of Calderón et al.[58], that reported acute toxicity of Mexican Gutierrezia microcephala (Asteraceae) on S. frugiperda larvae through AChE inhibition, in addition to reduced growth and delayed pupation.

Residual growth effects are often associated with insecticides but have largely been underexplored for Zanthoxylum extracts and other insecticidal compounds with AChE inhibition properties. Lack of any induced morphological aberrations associated with insect growth regulators at sublethal concentrations motivated our hypothesis that the ZCE/ZCFr. 5 treatment could have profound effects on the ecdysteroid 
pathway inducing larval retardation. The post-embryonic insect metamorphosis, associated with various morphological and behavioral changes particularly during the late third instar of larval-pupal transitions, is accompanied by $~ 100$-fold neurogenesis and neural remodeling events for the maturation of adultspecific neuronal lineages $[25,59,60]$. It has been demonstrated using various insect models that this phenomenon is coincidentally linked to ecdysteroid hormone activity regulated by stage-specific expression of biosynthetic Halloween CYP450 genes [61,62]. Since decreased mRNA levels of neuronal AChE gene could positively correlate with the observed changes in $20 \mathrm{E}$ biosynthetic enzymes and the fact that ecdysteroid receptor isoforms (EcR-A and EcR-B1) have been previously found in insect neuronal cells $[63,64]$, toxicity perturbation of these neurosecretory cells by ZCE constituents could have resulted in reduced biosynthesis, release and signaling, insufficient to influence ecdysone-mediated larval growth and pupation. These findings, akin to nicotinic acetylcholine receptor (nAChR) neonicotinoid effects, depicted that reduced expression of AChE influenced larval-pupal transition by perturbing ecdysteroidogenesis pathway. It is possible to postulate that tissue injuries on the developing larvae imparted by the larvicide treatment could have severely constrained ecdysteroid biosynthesis, hemolymph titres and signaling, arresting growth to allow regeneration as previously observed in Drosophila[65]. Furthermore, it could be possible that these cholinergic injuries had negative effects on larval prothoracic gland (PG) innervations among them the 5-hydroxytryptamine (5HT)-producing serotonergic neurons [66] modulating inositol 1,4,5-triphosphate/calcium $\left(\mathrm{InsP}_{3} / \mathrm{Ca}^{2+}\right.$ ) signaling pathway and reducing downstream ecdysone production that deprived pupal transformation. Nevertheless, the perturbed expression of steroidogenic CYP450s and especially spook (Cyp307a1) in the hypothetical ratelimiting "black box" clearly suggested either a partial or an absolute inhibition of 7-dehydrocholesterol (7dC) conversion to $5 \mathrm{~b}$-ketodiol resulting into diminished activation of $E c R$ and effector signaling transcription factors $E 75 A$ and $\beta F t z-F 1$. In fact the genetic loss and/or RNAi-mediated gene silencing of spook results in slowed development and molting interference that impairs growth $[67,68]$ due to low ecdysteroid titres as the prothoracicotropic hormone (PTTH) target SPOOK translation and phosphorylation in the "black box" for ecdysteroidogenesis. Additionally, the low hemolymph 20E titers in treated larvae were accompanied by slightly high JH levels (Fig. 4C-D) that agreeably sustained the phenotypic expression of larval retardants. Disruption of enzymes and genes associated with ecdysteroid biosynthetic and signaling pathway by plant-derived compounds has been investigated extensively [69]. Therefore, treatment with lignans and neolignans disrupts insect development by destabilizing steroid hormones [46]. Sesamin inhibits CYP3A4 by antagonizing steroid nuclear receptor [70], and its presence and abundance in ZCE (Fig. 2B) could have had significant inhibitory effects on ecdysteroid CYP450s and $20 \mathrm{E}$ response effectors due to its methylene dioxy phenyl (piperonyl) structure. Moreover, the previously observed retardant effects caused by plant-derived 2-tridecanone on $\mathrm{H}$. armigera as a result of down-regulation of $20 \mathrm{E}$ biosynthetic genes, particularly Сyp307a 1 could also be involved in this study [46]. Previous studies further demonstrated inhibitory regulation of CYP450s by saturated and unsaturated fatty acids [71,72], and the exogenous presence of linoleic acid and palmitic acid alongside other compounds in the hexane-soluble fraction could interfere with hormonal metabolism in developing mosquito larvae. 
Our findings demonstrate that $Z$. chalybeum root constituents are acutely toxic to mosquito larvae. This toxicity being mediated through disruption of neuromuscular coordination and further dysregulating ecdysteroidogenic-associated CYP450s at sublethal doses deserves further toxicological investigations aimed at designing potential mosquito control agents. Additionally, with the promising larvicidal effects herein demonstrated, we propose a comprehensive environmental safety assessment of ZCE constituents on non-target organisms prior to the commercial formulation, recommendation, and application in disease vector control programmes.

\section{Experimental Procedures}

\section{Mosquito larvae}

Experimental bioassays were performed with third instar mosquito larvae (L3) of insecticide-susceptible An. gambiae (Mbita strain) and Ae. aegypti obtained from a mosquito culture maintained at the International Centre of Insect Physiology and Ecology (icipe), Nairobi. The insects were maintained as previously described [5] at a density of 200 larvae per $1 \mathrm{~L}$ of dechlorinated water under controlled insectarium conditions: temperature $30 \pm 2^{\circ} \mathrm{C}, 60-80 \%$ relative humidity $(\mathrm{RH})$, and 12-h light/dark cycles. Throughout the experimental period, the larvae were fed on Tetramin fish meal (Tetra ${ }^{\circledR}$, Melle, Germany).

\section{Plant material, extraction, and fractionation}

Root samples of Z. chalybeum (Rutaceae) were collected in June 2018 from Mathemba village (GPS coordinates: $01^{\circ} 53^{\prime} 22.7^{\prime \prime} S, 037^{\circ} 45^{\prime} 11.1^{\prime \prime E}$; elevation 1114 m a.s.I), Makueni County, Kenya. The plant materials were authenticated by botanist Mr. Patrick C.B. Mutiso of the University of Nairobi Herbarium where a specimen voucher (JMM2018/06) is deposited for reference. Soil debris was removed with tap water, and the barks separated from the roots. The root barks were then size-reduced $(2-3 \mathrm{~cm})$, and shadedried at room temperature for two weeks, after which they were milled into powder using an electric mill (Retsch 200, Haan, Germany). To extract the bioactive agents, $90 \mathrm{~g}$ of the bark powder was soaked three times in $500 \mathrm{~mL}$ methanol for 3 days with intermittent shaking, after which the extract was filtered and concentrated via rotary evaporator (Laborota 4000 Efficient, Heidolph, Germany) yielding $49 \mathrm{~g}$ of brownyellow oily extract. The marc was adsorbed in silica gel (Kiesegel $60 \mathrm{M}$ [0.004-0.063 mm mesh size], Macharey-Nagel GmbH \& Co.KG, Düren, Germany) and loaded on silica gel-packed column. Fractionation was performed through an increasing gradient solvent system of EtOAc in $n$-hexane (1:0, 9:1, 4:1, 7:3, 3:2, $1: 1,2: 3,3: 7,1: 4,1: 9,0: 1)$ and finally $100 \% \mathrm{MeOH}$ yielding $23100-\mathrm{mL}$ fractions. The resultant fractions were rotor evaporated to $\sim 0.5 \mathrm{~mL}$, pooled into 12 major fractions (ZCFr.1-12) by TLC monitoring, air-dried and stored at $-20^{\circ} \mathrm{C}$ until screened for bioactivity.

\section{Mosquito bioassays}

Larvicidal bioassays were set up as outlined in WHO guidelines[73] under controlled insectarium rearing conditions. Preliminary assay with ZCE at $25-500$ ppm revealed $100 \%$ mosquito larval mortality within $<3$ h, prompting lower dosages. Late third instar (L3) mosquito larvae $(n=25)$ were separately introduced 
into five beakers containing $100 \mathrm{~mL}$ of test solutions at different concentrations (5-25 ppm and 1-10 ppm of ZCE and its solvent fractions, respectively). These test solutions were separately formulated in $0.01 \%$ $(v / v)$ ethanol and dispensed into respective beakers for the assays. A parallel experimental setup containing essential oil of neem rich in triterpenoid azadirachtin which is a potent larvicide was used as positive control while the negative control setup constituted mosquito larvae in water with $0.01 \%(\mathrm{~V} / \mathrm{v})$ ethanol. Larval mortalities in each experimental setup were recorded in each experimental replicate for 24-h post-treatment. To assess the effects of ZCE and its active fraction (ZCFr.5) on larval development, 20 newly molted (synchronous) early L3 instars (4-5 days post egg hatching) added into three beakers were treated with sublethal dosages (ZCE: 8 ppm, 10 ppm; ZCFr.5: 1.0 ppm, 3 ppm for An. gambiae, and Ae. aegypti, respectively). Time taken for the mosquito larvae to reach pupal stages was recorded, and percentage pupation for each treatment replicate calculated $(n=3)$. Parallel setups constituting distilled water and $0.01 \%$ ethanol served as references.

\section{Phytochemical analysis}

Activity-based screening revealed a highly toxic $n$-hexane-soluble fraction (ZCFr.5, eluted in 3:2 hexane/EtOAc gradient) against mosquito larvae (Table 1, Supplementary Table S1). To identify the chemical entities eliciting the toxicity effects, a GC/MS-TQ8040 system (Shidmazu Corp., Kyoto, Japan) equipped with a mass selective detector and fitted with a silica capillary column (SH-Rxi-5HT; $30 \mathrm{~m} \times 0.25$ $\mathrm{mm}$ internal diameter $\times 0.25 \mu \mathrm{m}$ film thickness) was used for analysis. Ultra-pure grade helium at a flow rate of $1.44 \mathrm{~mL} / \mathrm{min}$ was used as the carrier gas. The injector temperature was maintained at $280^{\circ} \mathrm{C}$, and a sample volume of $1 \mu \mathrm{L}$ injected. The initial oven temperature was programmed at $80^{\circ} \mathrm{C}$ for 5 min then ramped at rates of $15^{\circ} \mathrm{C} / \mathrm{min}$ to $280^{\circ} \mathrm{C}$ (held for $8 \mathrm{~min}$ ). For data acquisition, the GC-MS was operated in the full scan mode with Shimadzu's GC-MS Smart Pesticide Database (version 1) used as a foundation of analysis and identification of analytes.

\section{Total RNA isolation, cDNA synthesis, and RT-qPCR analyses}

Total RNA was isolated from pools of five mosquito larvae obtained from ZCFr.5-treated and non-treated control groups using TRIzol reagent (Invitrogen ${ }^{\text {TM }}$, Carlsbad, CA 92008, USA) according to manufacturer's guidelines. To assess the purity and concentrations of the isolated RNA, a Nanodrop 2000 UV Vis spectrophotometer (Thermo Scientific, USA) was used. cDNA first strand was synthesized from DNase I treated total RNA (500 ng) using oligo d $(\mathrm{T})_{20}$ primers of SuperScript ${ }^{\circledR}$ IV First-Strand Synthesis System (Invitrogen Life Technologies, Lithuania) as per manufacturer's instructions. Gene expression analyses were performed using Agilent Stratagene Mx3005P real time qPCR system (Agilent technologies, USA) with SYBR Green ${ }^{\circledR} /$ ROX $q$ PCR master mix (Thermo Scientific, USA). Primers used for RT-qPCR analyses are listed in Supplementary Table S4. Gene-specific amplification reaction comprised of $6.25 \mu \mathrm{L}$ SYBR Green/ROX, 0.5 picomoles of forward and reverse primers, $1 \mu \mathrm{L}$ of 1:5 diluted cDNA, and topped up to $12.5 \mu \mathrm{L}$ with nuclease-free water. The PCR cycling conditions were programmed as follows; initial step $95^{\circ} \mathrm{C}$ for $10 \mathrm{~min}, 40 \mathrm{cycles}$ of $95^{\circ} \mathrm{C}$ for $30 \mathrm{sec}, 60^{\circ} \mathrm{C}$ for $30 \mathrm{sec}$, and $72^{\circ} \mathrm{C}$ for $30 \mathrm{sec}$ followed by a single cycle of dissociation melt curve set at $95^{\circ} \mathrm{C}$ for $30 \mathrm{sec}, 55^{\circ} \mathrm{C}$ for $1 \mathrm{~min}$ and $95^{\circ} \mathrm{C}$ for $30 \mathrm{sec}$. Normalization 
of the gene expression levels was performed using species-specific ribosomal protein S7. All the experiments were performed three times. The relative gene expression levels were analyzed using $2^{-\Delta \Delta C t}$ method [74].

\section{Biochemical acetylcholinesterase (AChE) enzymatic assay}

Ellman's protocol [75] with minor modifications was followed to measure the AChE inhibitory activities of ZCE. A pool of 10 larvae from each species was separately washed three times in phosphate buffer (1X PBS, pH 8.0) before homogenization in $1 \mathrm{~mL}$ PBS. The homogenates were centrifuged at $10,625 \times \mathrm{g}$ for $20 \mathrm{~min}$ at $4^{\circ} \mathrm{C}$ and supernatants separately transferred into sterile clean 1.5-mL Eppendorf tubes to give the enzyme extract source for assaying. Into $150 \mu \mathrm{L}$ of ice-cold PBS held in 96-wells plate, $10 \mu \mathrm{L}$ of the enzyme extract was added before addition $20 \mu \mathrm{L}$ of test extract preparations. The test extracts were dissolved in DMSO to a final concentration of $0.1 \%$ DMSO $(w / v)$ in PBS. The reactants were incubated at room temperature for $10 \mathrm{~min}$ followed by the addition of $20 \mu \mathrm{L} 0.4 \mu \mathrm{M}$ acetylthioiodide (ATChl, BDH Chemicals Ltd, England) and $0.3 \mu \mathrm{M}$ 5,5'-DTNB (Ellman's reagent, Sigma Aldrich, USA). This was followed by a 30-min incubation at room temperature and absorbance read out using an Eppendorf BioSpectrometer ${ }^{\circledR}$ Fluorescence at $412 \mathrm{~nm}$. A set up comprising of enzyme extract, DTNB, and the buffer was used as blank while a positive reaction constituted the enzyme extract, ATChl, and DTNB. A commercial chemical Propoxur (PESTANAL ${ }^{\circledR}$ analytical standard, Sigma Aldrich, USA) was included as the reference inhibitor. The assay was performed in four replicates and the $\%$ AChE inhibition expressed as a mean value of the replicates as given in equation (1) below;

$\%$ Inhibition $=\left(1-\frac{\text { Absorbance in sample reaction }}{\text { Absorbance in control reaction }}\right) \times 100$

\section{Statistical data analyses}

A generalized non-linear regression model ( $\mathrm{glm}$ ) was fitted in R software (version 3.5.1) to estimate the half-maximal lethal $\left(\mathrm{LC}_{50}\right)$ and inhibitory $\left(\mathrm{IC}_{50}\right)$ concentrations using probit link function and dose.p function in MASS package. Mean differences in experimental data were compared by one-way ANOVA with Tukey's post-hoc analyses or Student's $t$-test and $p$ values of less than 0.05 considered statistically significant. Correlations between mean $\mathrm{LC}_{50 \text { s }}$ and $\mathrm{AChE}$ inhibition was performed using Pearson's correlation coefficient (r). Graphpad Prism 7.0 (Prism 7 for Windows, GraphPad software, Inc., USA) was deployed to generate high-quality graphics.

\section{List Of Abbreviations}

ZCE: Zanthoxylum chalybeum extract; AChE: Acetyl cholinesterase; CYP450: cytochrome p450; 20E: 20hydroxyecydysone; ECR: Ecdysteroid receptor; $\mathrm{LC}_{50}$ : Lethal concentration at 50\% test population; icipe: 
International Centre of Insect Physiology and Ecology; PBS: Phosphate Buffered Saline; DMSO: Dimethyl sulfoxide; DTNB: 5,5'-Dithiobis(2-nitrobenzoic acid)

\section{Declarations}

\section{Acknowledgements}

The authors acknowledge the technical support of icipe's Ms. Milkah Gitau for assistance in mosquito breeding. We are sincerely grateful for the support awarded to G.O.A under Alexander von Humboldt Foundation Postdoctoral Fellowship. Jackson is a recipient of the Kenyan Higher Education Loans Board (HELB) Postgraduate Scholarship, while S.N.N. is supported by DAAD/NACOSTI Fellowship and the International Foundation of Science (IFS) grant \# F/5372-1. J.L.B. is supported by IFS grant\# B/5925-1, Cambridge-Africa Alborada Fund 2017/18, The Global Challenges Research Fund - Pump-Priming Fund (GCRF grant \#G100049/17588), and DELTAS Africa Initiative grant \# DEL-15-011 to THRiVE-2. The DELTAS Africa Initiative is an independent funding scheme of the African Academy of Sciences (AAS)'s Alliance for Accelerating Excellence in Science in Africa (AESA) and supported by the New Partnership for Africa's Development Planning and Coordinating Agency (NEPAD Agency) with funding from the Wellcome Trust grant \# 107742/Z/15/Z and the UK government. The views expressed in this publication are those of the authors and not necessarily those of AAS, NEPAD Agency, Wellcome Trust or the UK government, or their respective employers.

\section{Ethics approval and consent to participate}

Not applicable

\section{Author contributions}

Jackson, J.L.B. and S.N.N. conceptualized and designed the study experiments. Jackson carried out the experiments, performed data analyses, and wrote the first manuscript draft. J.L.B., James, M.A.O., G.O.A., and S.N.N. provided the study materials and supervision throughout the study, guidance, and revision of the manuscript. All authors reviewed and approved the final version.

\section{Competing interests}

The authors declare that they have no conflicts of interest with the contents of this article.

\section{Data availability}

All data generated or analyzed during this study are included in this article and supplementary files.

\section{References}


1. George D, Finn R, Graham K, Sparagano O. Present and future potential of plant-derived products to control arthropods of veterinary and medical significance. Parasit Vectors. 2014;7:28.

2. Muema JM, Bargul JL, Njeru SN, Onyango JO, Imbahale SS. Prospects for malaria control through manipulation of mosquito larval habitats and olfactory-mediated behavioural responses using plantderived compounds. Parasit Vectors. 2017;10:184.

3. Lengai GMW, Muthomi JW, Mbega ER. Phytochemical activity and role of botanical pesticides in pest management for sustainable agricultural crop production. Sci African. 2019;e00239.

4. Mithöfer A, Boland W. Plant defense against herbivores: Chemical aspects. Annu Rev Plant Biol. 2012;63:431-50.

5. Muema JM, Nyanjom SG, Mutunga JM, Njeru SN, Bargul JL. Green tea proanthocyanidins cause impairment of hormone-regulated larval development and reproductive fitness via repression of juvenile hormone acid methyltransferase, insulin-like peptide and cytochrome P450 genes in Anopheles gambiae sensu stricto. PLoS One. 2017;12:e0173564.

6. Lee S-H, Oh H-W, Fang Y, An S-B, Park D-S, Song H-H, et al. Identification of plant compounds that disrupt the insect juvenile hormone receptor complex. Proc Natl Acad Sci. National Acad Sciences; 2015;112:1733-8.

7. da Silva Costa M, de Paula SO, Martins GF, Zanuncio JC, Santana AEG, Serrão JE. Multiple modes of action of the squamocin in the midgut cells of Aedes aegypti larvae. PLoS One. 2016;11:e0160928.

8. Hematpoor A, Liew SY, Chong WL, Azirun MS, Lee VS, Awang K. Inhibition and larvicidal activity of phenylpropanoids from Piper sarmentosum on acetylcholinesterase against mosquito vectors and their binding mode of interaction. PLoS One. 2016;11:e0155265.

9. Niwa YS, Niwa R. Neural control of steroid hormone biosynthesis during development in the fruit fly Drosophila melanogaster. Genes Genet Syst. 2014;89:27-34.

10. Koyama T, Mirth CK. Unravelling the diversity of mechanisms through which nutrition regulates body size in insects. Curr Opin Insect Sci. 2018;25:1-8.

11. Ou Q, Zeng J, Yamanaka N, Brakken-Thal C, O'Connor MB, King-Jones K. The insect prothoracic gland as a model for steroid hormone biosynthesis and regulation. Cell Rep. 2016;16:247-62.

12. Pankotai T, Popescu C, Martin D, Grau B, Zsindely N, Bodai L, et al. Genes of the ecdysone biosynthesis pathway are regulated by the dATAC histone acetyltransferase complex in Drosophila. Mol Cell Biol. 2010;30:4254-66.

13. Niwa YS, Niwa R. Transcriptional regulation of insect steroid hormone biosynthesis and its role in controlling timing of molting and metamorphosis. Dev Growth Differ. 2016;58:94-105.

14. Fletcher JC, Thummel CS. The Ecdysone-inducible Broad-complex and E74 early genes interact to regulate target gene transcription and Drosophila metamorphosis. Genetics. 1995;141:1025-35.

15. Toutant J-P. Insect acetylcholinesterase: Catalytic properties, tissue distribution and molecular forms. Prog Neurobiol. 1989;32:423-46. 
16. Soreq H, Seidman S. Acetylcholinesterase - new roles for an old actor. Nat Rev Neurosci. 2001;2:294.

17. Pang Y-P, Brimijoin S, Ragsdale DW, Zhu KY, Suranyi R. Novel and viable acetylcholinesterase target site for developing effective and environmentally safe insecticides. Curr Drug Targets. 2012;13:47182.

18. Dou D, Park JG, Rana S, Madden BJ, Jiang H, Pang Y-P. Novel selective and irreversible mosquito acetylcholinesterase inhibitors for controlling malaria and other mosquito-borne diseases. Sci Rep. 2013;3:1068.

19. Mutunga JM, Ma M, Chen Q-H, Hartsel JA, Wong DM, Ding S, et al. Mosquito acetylcholinesterase as a target for novel phenyl-substituted carbamates. Int J Environ Res Public Health 2019;16:1500.

20. Kumar M, Gupta GP, Rajam MV. Silencing of acetylcholinesterase gene of Helicoverpa armigera by siRNA affects larval growth and its life cycle. J Insect Physiol. 2009;55:273-8.

21. Ye X, Yang L, Stanley D, Li F, Fang Q. Two Bombyx mori acetylcholinesterase genes influence motor control and development in different ways. Sci Rep. 2017;7:4985.

22. Hui X, Yang L, He G, Yang Q, Han Z, Li F. RNA interference of ace1 and ace2 in Chilo suppressalis reveals their different contributions to motor ability and larval growth. Insect Mol Biol. 2011;20:50718.

23. He G, Sun Y, Li F. RNA interference of two acetylcholinesterase genes in Plutella xylostella reveals their different functions. Arch Insect Biochem Physiol. 2012;79:75-86.

24. Lu Y, Park Y, Gao X, Zhang X, Yao J, Pang Y-P, et al. Cholinergic and non-cholinergic functions of two acetylcholinesterase genes revealed by gene-silencing in Tribolium castaneum. Sci Rep. 2012;2:288.

25. Malik HJ, Raza A, Amin I, Scheffler JA, Scheffler BE, Brown JK, et al. RNAi-mediated mortality of the whitefly through transgenic expression of double-stranded RNA homologous to acetylcholinesterase and ecdysone receptor in tobacco plants. Sci Rep. 2016;6:38469.

26. Saini RP, Raman V, Dhandapani G, Malhotra EV, Sreevathsa R, Kumar PA, et al. Silencing of HaAce1 gene by host-delivered artificial microRNA disrupts growth and development of Helicoverpa armigera. PLoS One. 2018;13:e0194150.

27. Cohen E. Acetylcholinesterase activity in an Aedes aegypti cell line. Experientia. Springer; 1981;37:429-31.

28. Spindler-Barth M, Schmidt H, Drews U, Spindler K-D. Increase in activity of acetylcholinesterase by 20 OH-ecdysone in a Chironomus tentans cell line. Arch Dev Biol. 1988;197:366-9.

29. Jean-Jacques L, Jean-Paul D, Jean G. Developmental changes and acetylcholinesterase activity in the metamorphosing brain of Tenebrio molitor. Correlation to ecdysteroid titers. Arch Insect Biochem Physiol. 2005;25:207-26.

30. Jenson LJ, Paulson SL, Bloomquist JR. Induction and inhibition of an apparent neuronal phenotype in Spodoptera frugiperda insect cells (Sf21) by chemical agents. Invertebr Neurosci. 2012;12:11927. 
31. Novicki A, Weeks JC. Organization of the larval pre-ecdysis motor pattern in the tobacco hornworm, Manduca sexta. J Comp Physiol A. 1993;173:151-62.

32. Truman JW. Steroid receptors and nervous system metamorphosis in insects. Dev Neurosci. 1996;18:87-101.

33. Veverytsa L, Allan DW. Subtype-specific neuronal remodeling during Drosophila metamorphosis. Fly (Austin). 2013;7:78-86.

34. Tusting LS, Thwing J, Sinclair D, Fillinger U, Gimnig J, Bonner KE, et al. Mosquito larval source management for controlling malaria. Cochrane database Syst Rev. 2013;8:CD008923-CD008923.

35. Gianotti RL, Bomblies A, Dafalla M, Issa-Arzika I, Duchemin J-B, Eltahir EAB. Efficacy of local neem extracts for sustainable malaria vector control in an African village. Malar J. 2008;7:138.

36. Trudel RE, Bomblies A. Larvicidal effects of Chinaberry (Melia azederach) powder on Anopheles arabiensis in Ethiopia. Parasit Vectors. BioMed Central Ltd; 2011;4:72.

37. Imbahale SS, Mukabana WR. Efficacy of neem chippings for mosquito larval control under field conditions. BMC Ecol. 2015;15:1.

38. Demissew A, Balkew M, Girma M. Larvicidal activities of chinaberry, neem and Bacillus thuringiensis israelensis (Bti) to an insecticide resistant population of Anopheles arabiensis from Tolay, Southwest Ethiopia. Asian Pac J Trop Biomed. 2016;6:554-61.

39. Zhang Y, Peng Y, Chen F, Zeng D, Huang Yl, Zhong H. Bioactivity and components of essential oil from Zanthoxylum ailanthoides fruits against two mosquito species. Acta Entomol Sin. 2009;52:1028-33.

40. Overgaard HJ, Sirisopa P, Mikolo B, Malterud KE, Wangensteen H, Zou Y-F, et al. Insecticidal activities of bark, leaf and seed extracts of Zanthoxylum heitzii against the African malaria vector Anopheles gambiae. Molecules. 2014;19:21276-90.

41. Moussavi N, Malterud KE, Mikolo B, Dawes D, Chandre F, Corbel V, et al. Identification of chemical constituents of Zanthoxylum heitzii stem bark and their insecticidal activity against the malaria mosquito Anopheles gambiae. Parasit Vectors. 2015;1-8.

42. Kim S-I, Ahn Y-J. Larvicidal activity of lignans and alkaloid identified in Zanthoxylum piperitum bark toward insecticide-susceptible and wild Culex pipiens pallens and Aedes aegypti. Parasit Vectors. 2017;10:221.

43. Pavela R, Govindarajan M. The essential oil from Zanthoxylum monophyllum a potential mosquito larvicide with low toxicity to the non-target fish Gambusia affinis. J Pest Sci 2017;90:369-78.

44. Zhang L, Lu Y, Xiang M, Shang Q, Gao X. The retardant effect of 2-Tridecanone, mediated by cytochrome P450, on the development of cotton bollworm, Helicoverpa armigera. BMC Genomics. 2016;17:954.

45. Tomé HV, Pascini T V, Dângelo RA, Guedes RN, Martins GF. Survival and swimming behavior of insecticide-exposed larvae and pupae of the yellow fever mosquito Aedes aegypti. Parasit Vectors. 2014;7:195. 
46. Harmatha J, Dinan L. Biological activities of lignans and stilbenoids associated with plant-insect chemical interactions. Phytochem Rev. 2003;2:321-30.

47. He Q, Wang W, Zhu L. Larvicidal activity of Zanthoxylum acanthopodium essential oil against the malaria mosquitoes, Anopheles anthropophagus and Anopheles sinensis. Malar J. 2018;17:194.

48. Kokate SD, Venkatachalam SR, Hassarajani SA. Zanthoxylum alatum extract as mosquito larvicide. PROCEEDINGS-NATIONAL Acad Sci INDIA Sect B. 2001;71:229-32.

49. Kamsuk K, Choochote W, Chaithong U, Jitpakdi A, Tippawangkosol P, Riyong D, et al. Effectiveness of Zanthoxylum piperitum-derived essential oil as an alternative repellent under laboratory and field applications. Parasitol Res. 2007;100:339.

50. Tiwary M, Naik SN, Tewary DK, Mittal PK, Yadav S. Chemical composition and larvicidal activities of the essential oil of Zanthoxylum armatum DC (Rutaceae) against three mosquito vectors. J Vector Borne Dis. 2007;44:198.

51. Matasyoh JC, Talontsi FM, Ngoumfo RM, Chepkorir R. Larvicidal activity of acridone alkaloids from Zanthoxy/um leprieurii against the malaria vector Anopheles gambiae. Nat Prod J. 2011;1:121-4.

52. Talontsi FM, Matasyoh JC, Ngoumfo RM, Chepkorir R. Mosquito larvicidal activity of alkaloids from Zanthoxylum lemairei against the malaria vector Anopheles gambiae. Pestic Biochem Physiol. 2011;99:82-5.

53. Liu XC, Liu QY, Zhou L, Liu QR, Liu ZL. Chemical composition of Zanthoxylum avicennae essential oil and its larvicidal activity on Aedes albopictus Skuse. Trop J Pharm Res. 2014;13:399-404.

54. Wang C-F, Yang K, You C-X, Zhang W-J, Guo S-S, Geng Z-F, et al. Chemical composition and insecticidal activity of essential oils from Zanthoxy/um dissitum leaves and roots against three species of storage pests. Molecules. 2015;20:7990-9.

55. Kimps NW, Bissinger BW, Apperson CS, Sonenshine DE, Roe RM. First report of the repellency of 2tridecanone against ticks. Med Vet Entomol. 2011;25:202-8.

56. Innocent E, Gikonyo NK, Nkunya MH. Repellency property of long chain aliphatic methyl ketones against Anopheles gambiaess. Tanzan J Health Res. 2008;10:50-4.

57. Perumalsamy H, Jang MJ, Kim J-R, Kadarkarai M, Ahn Y-J. Larvicidal activity and possible mode of action of four flavonoids and two fatty acids identified in Millettia pinnata seed toward three mosquito species. Parasit Vectors. 2015;8:237.

58. Calderón J, Carlos C, Rosaura R, Federico G-G, R SJ, R SJ, et al. Acetylcholinesterase and insect growth inhibitory activities of Gutierrezia microcephala on Fall Army worm Spodoptera frugiperda J. E. Smith. Zeitschrift für Naturforsch. C. 2001. p. 382.

59. Kent KS, Consoulas C, Duncan K, Johnston RM, Luedeman R, Levine RB. Remodelling of neuromuscular systems during insect metamorphosis. Am Zool. 1995;35:578-84.

60. Truman JW, Reiss SE. Neuromuscular metamorphosis in the moth Manduca sexta: hormonal regulation of synapses loss and remodeling. J Neurosci. 1995;15:4815-26. 
61. Li H, Cooper RL. Effects of the ecdysoneless mutant on synaptic efficacy and structure at the neuromuscular junction in Drosophila larvae during normal and prolonged development. Neuroscience. 2001;106:193-200.

62. White BH, Ewer J. Neural and hormonal control of postecdysial behaviors in insects. Annu Rev Entomol. 2014;59:363-81.

63. Truman JW, Talbot WS, Fahrbach SE, Hogness DS. Ecdysone receptor expression in the CNS correlates with stage-specific responses to ecdysteroids during Drosophila and Manduca development. Development. 1994;120:219 LP-234.

64. Schubiger M, Wade AA, Carney GE, Truman JW, Bender M. Drosophila EcR-B ecdysone receptor isoforms are required for larval molting and for neuron remodeling during metamorphosis. Development. 1998;125:2053-62.

65. Hackney JF, Zolali-Meybodi O, Cherbas P. Tissue damage disrupts developmental progression and ecdysteroid biosynthesis in Drosophila. PLoS One. 2012;7:e49105.

66. Shimada-Niwa Y, Niwa R. Serotonergic neurons respond to nutrients and regulate the timing of steroid hormone biosynthesis in Drosophila. Nat Commun. 2014;5:5778.

67. Namiki T, Niwa R, Sakudoh T, Shirai K, Takeuchi H, Kataoka H. Cytochrome P450 CYP307A1/Spook: A regulator for ecdysone synthesis in insects. Biochem Biophys Res Commun. 2005;337:367-74.

68. Sugahara R, Tanaka S, Shiotsuki T. RNAi-mediated knockdown of SPOOK reduces ecdysteroid titers and causes precocious metamorphosis in the desert locust Schistocerca gregaria. Dev Biol.2017;429:71-80.

69. Dinan L. Phytoecdysteroids: biological aspects. Phytochemistry. 2001;57:325-39.

70. Lim Y-P, Ma C-Y, Liu C-L, Lin Y-H, Hu M-L, Chen J-J, et al. Sesamin: a naturally occurring lignan inhibits CYP3A4 by antagonizing the pregnane $X$ receptor activation. Evidence-Based Complement Altern Med. 2012;2012:1-15.

71. Hirunpanich V, Sethabouppha B, Sato H. Inhibitory effects of saturated and polyunsaturated fatty acids on the cytochrome P450 3A activity in rat liver microsomes. Biol Pharm Bull. 2007;30:1586-8.

72. Palacharla RC, Uthukam V, Manoharan A, Ponnamaneni RK, Padala NP, Boggavarapu RK, et al. Inhibition of cytochrome P450 enzymes by saturated and unsaturated fatty acids in human liver microsomes, characterization of enzyme kinetics in the presence of bovine serum albumin ( 0.1 and $1.0 \% \mathrm{w} / \mathrm{v}$ ) and in vitro-in vivo extrapolation of hepatic clearanc. Eur J Pharm Sci. 2017;101:80-9.

73. WHO. Guidelines for laboratory and field testing of mosquito larvicides. World Heal Organ. 2005;141.

74. Livak KJ, Schmittgen TD. Analysis of relative gene expression data using real-time quantitative PCR and the 2- $\triangle \Delta C T$ method. methods. 2001;25:402-8.

75. Ellman GL, Courtney KD, Andres V, Featherstone RM. A new and rapid colorimetric determination of acetylcholinesterase activity. Biochem Pharmacol. 1961;7:88-95. 
Figures

A

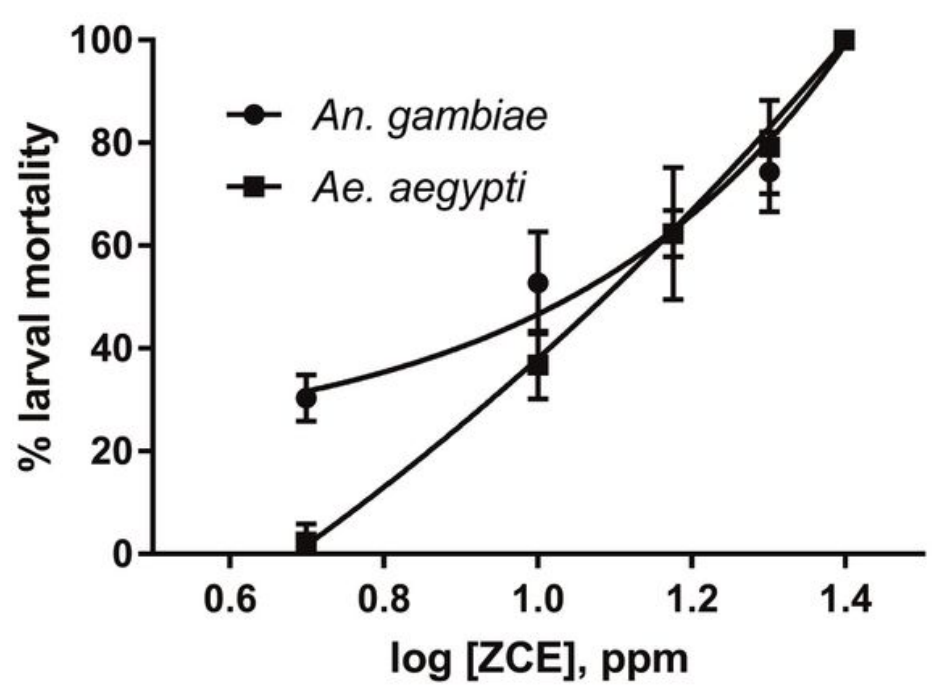

B

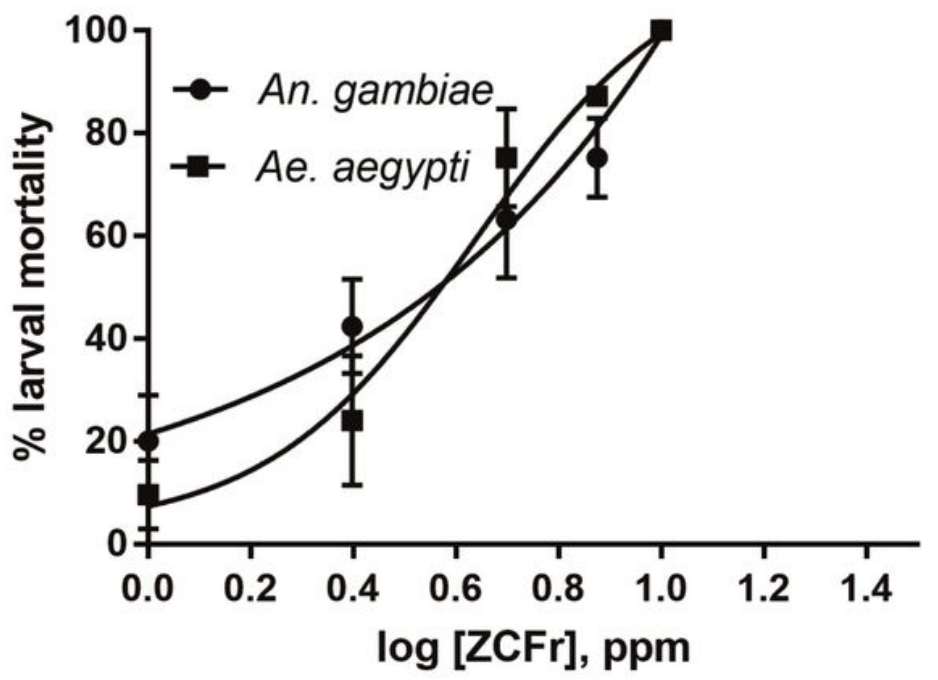

Figure 1

Normalized dose-response curves of An. gambiae and Ae. aegypti larvae to ZCE extracts at 24-h. (A): ZCE-treated larvae (B): ZCFr.5-treated larvae 


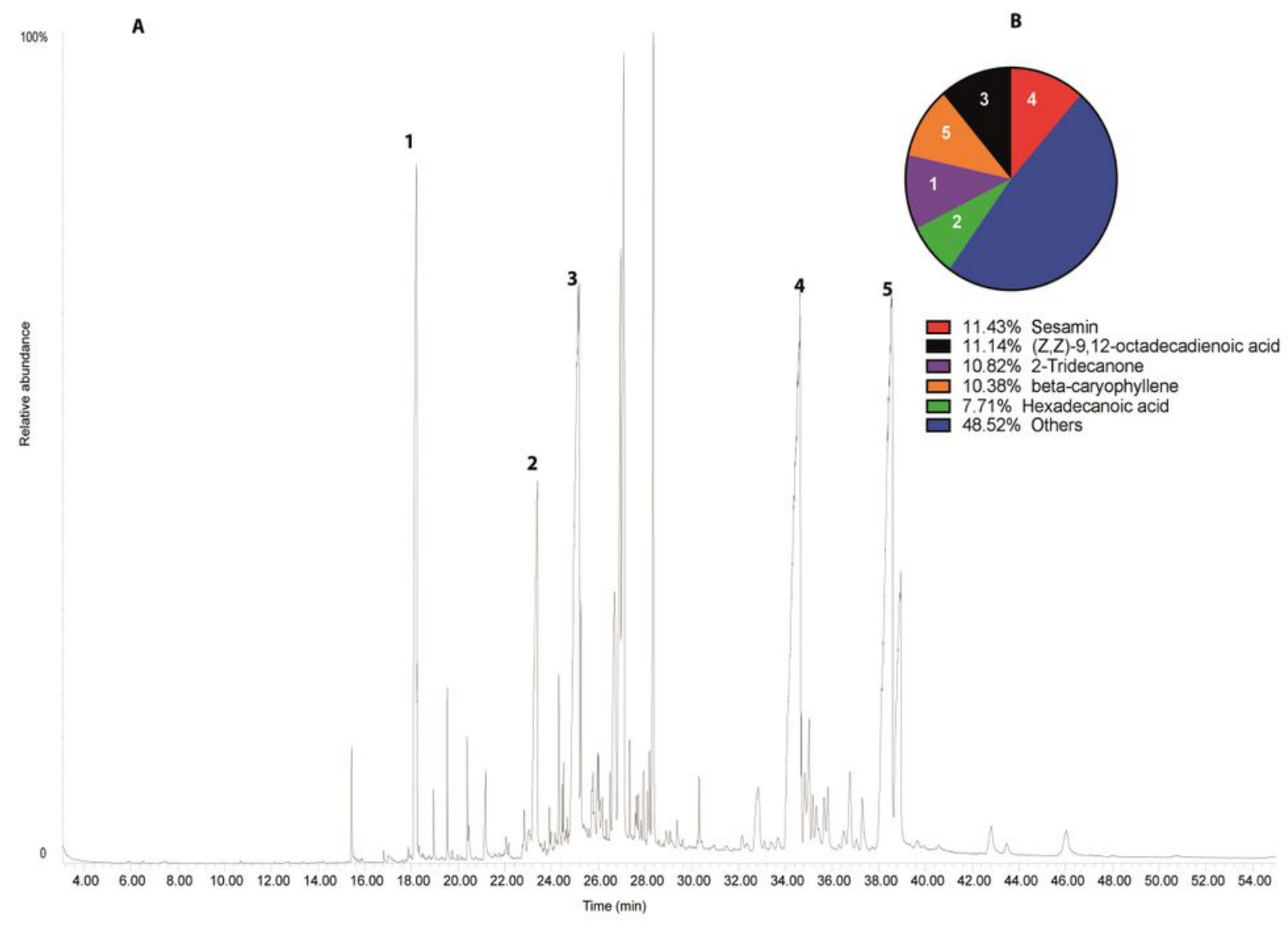

C<smiles>CCCCCCCCCCCC(C)=O</smiles><smiles>CCCCCCCCCCCCCCCC(=O)O</smiles><smiles>CCCCC/C=C\C/C=C\CCCCCCCC(=O)O</smiles><smiles>c1cc2c(cc1[C@H]1OC[C@H]3[C@H](c4ccc5c(c4)OCO5)OC[C@H]13)OCO2</smiles><smiles>C=C1CC/C=C(/C)CC[C@@H]2C[C@@H]1CC2(C)C</smiles>

\section{Figure 2}

Analysis of chemical constituents in bioactive fraction. (A): The total ion chromatographic of GC-MS analysis spectrum from hexane-soluble Z. chalybeum root fraction. (B): Relative proportions of the major compounds in bioactive biomass. (C): Chemical structures of the identified major compounds, (1): 2tridecanone, (2): hexadecanoic acid, (3): (Z,Z)-9,12-octadecadienoic acid, (4): sesamin, and (5): $\beta$ caryophyllene. 


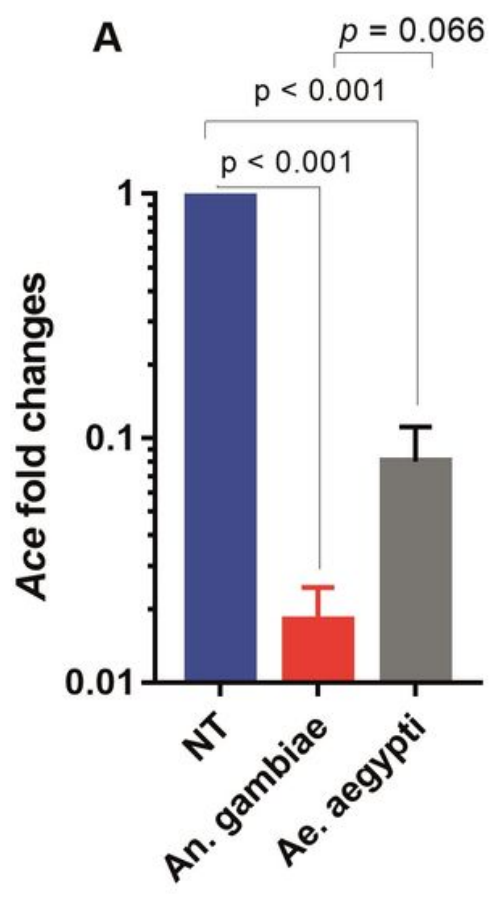

B

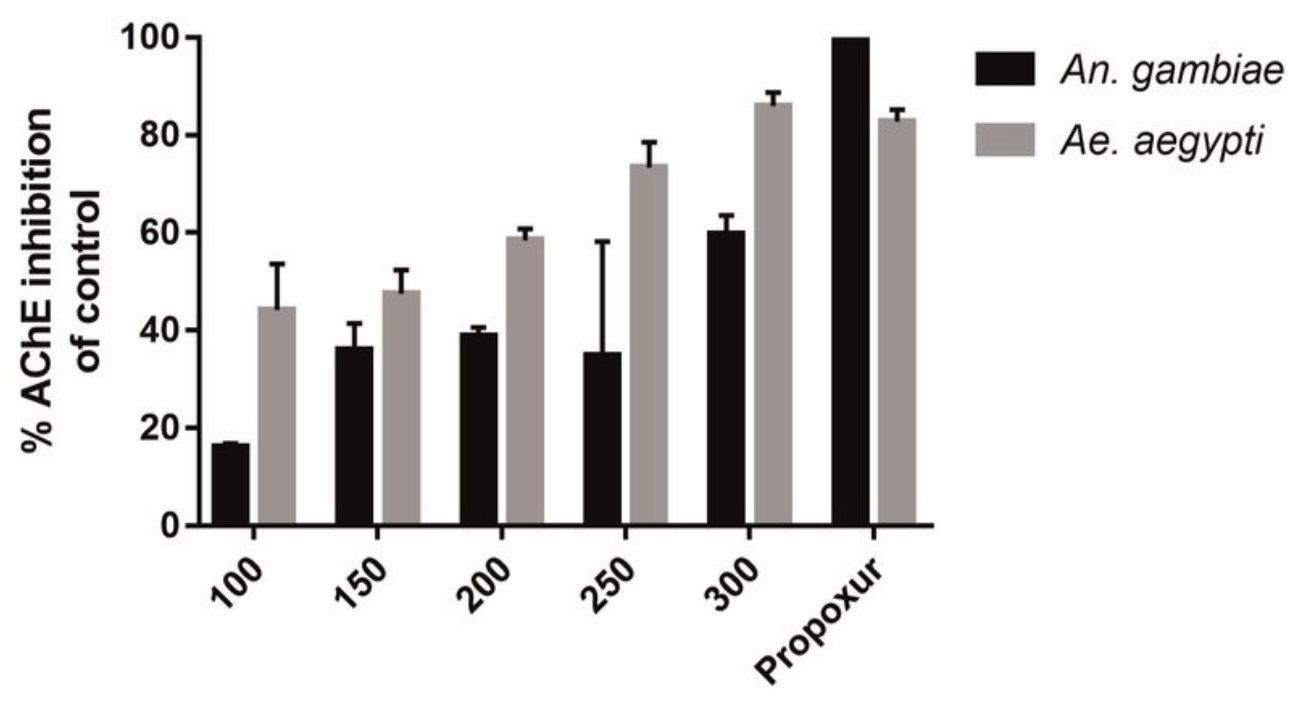

Treatments $(\mu \mathrm{g} / \mathrm{mL})$

\section{Figure 3}

Effects of larval treatment on acetylcholinesterase activity. (A): Change of AChE (Ace) gene expression following larval treatment with ZCE bioactive fraction (ZCFr.5) within 25 min. Variation in expression compared by Student's t-test for three independent replicates $(n=3)$. NT denotes non-treated control whose gene expression was adjusted to 1 for both mosquito species. (B): Normalized ZCE inhibitory activity of mosquito larval AChE (data presented as \% mean \pm S.D of $n=2$ biological replicates, 4 technical replicates). Propoxur was tested at $100 \mu \mathrm{g} / \mathrm{mL}$. 


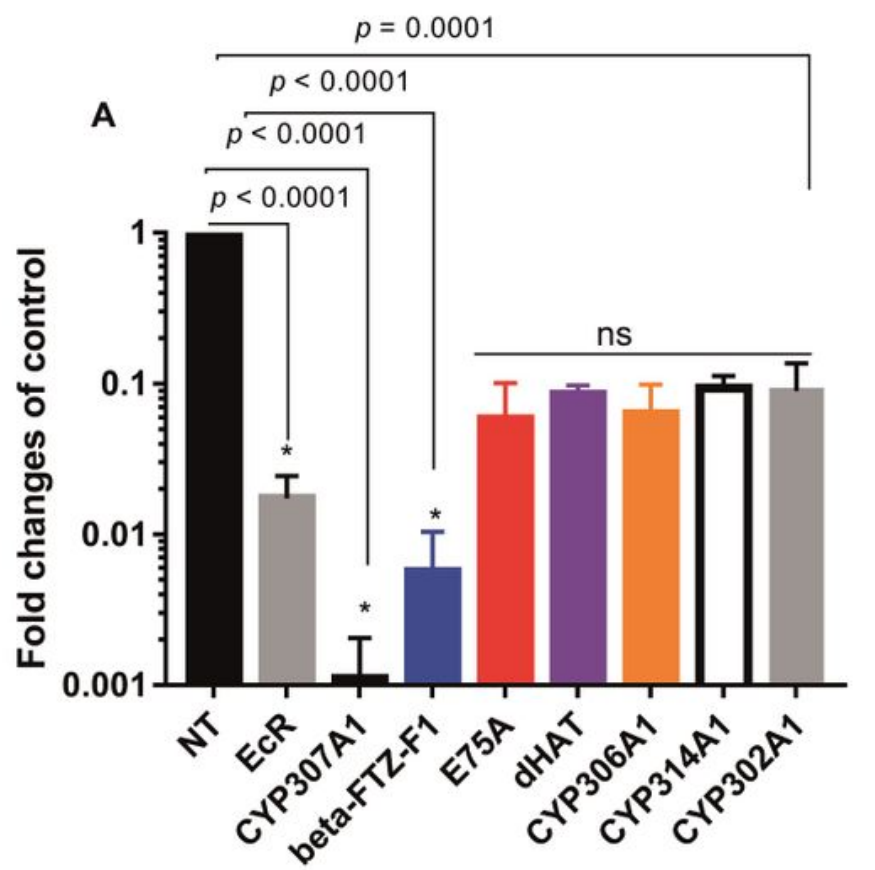

An. gambiae larval genes
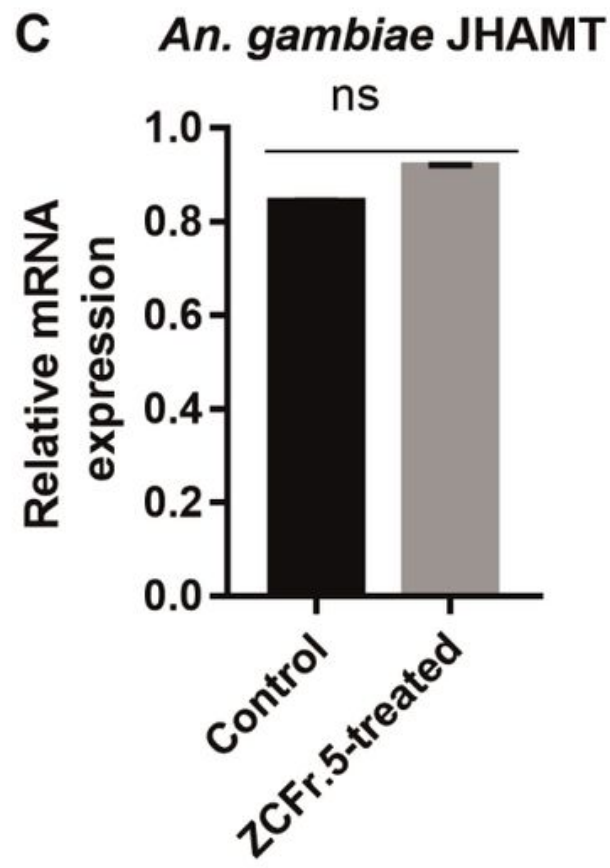

Treatments

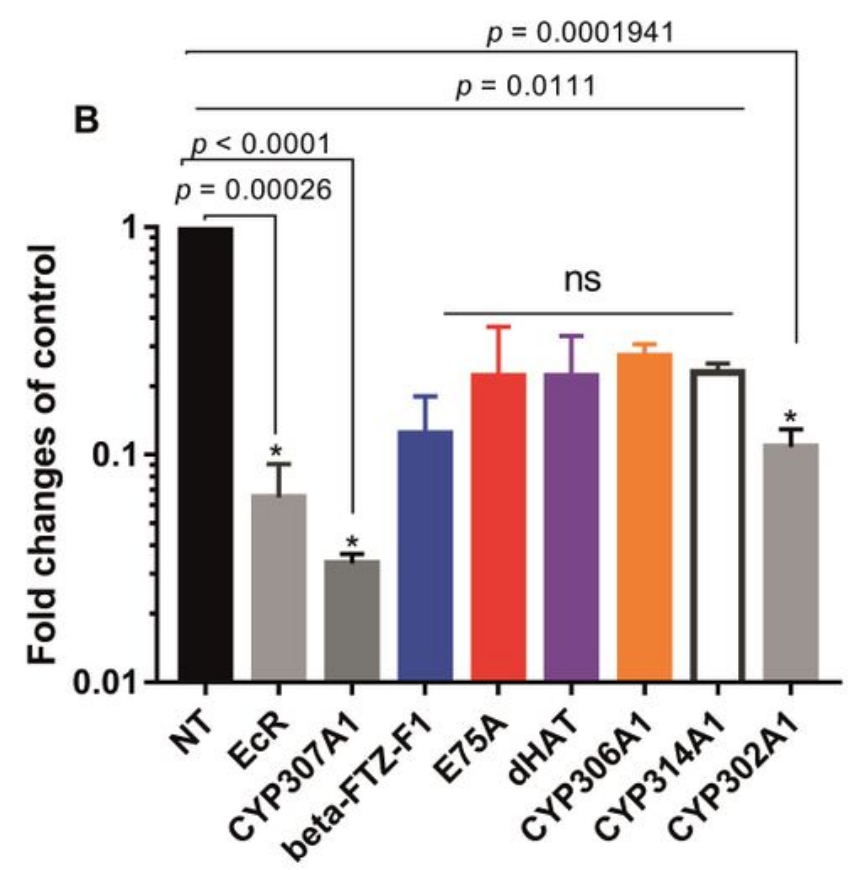

Ae. aegypti larval genes

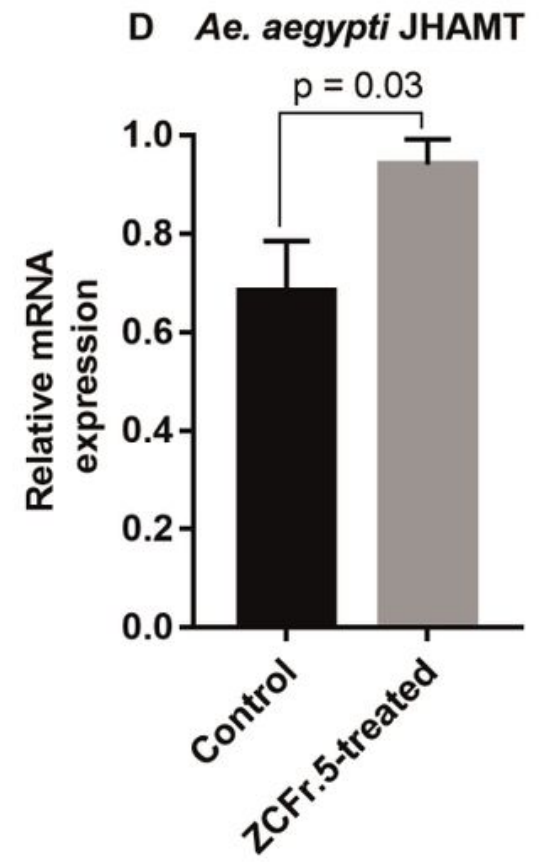

Treatments

Figure 4

Ecdysteroidogenic transcriptional gene profiles on larval treatment. A-B: Mean fold changes in gene expression levels of ZCFr.5-treated An. gambiae and Ae. aegypti larvae. Mosquito larvae were treated at sublethal doses (slightly below species-specific LC50 1 ppm for An. gambiae and 3 ppm for Ae. aegypti) for 72-h and gene expression assessed using RT-qPCR. Experimental controls were incubated with a solution containing $0.01 \%$ ethanol $(\mathrm{v} / \mathrm{v})$ in distilled water. Significant alterations in larval gene 
expressions were noted (t-test, $\mathrm{p}<0.01)$. *indicates statistically significant data at $\mathrm{p}<0.05$, ns - not significant from each other (Student's t-test), NT - Non-treated control whose gene expression was adjusted to 1 for both mosquito species. All the experimental assays were performed in triplicates $(n=3)$. C-D: Expression profiles of JHAMT in ZCFr.5-treated larvae relative to non-treated control groups. Data are expressed as mean \pm S.D of experimental replicates.

\section{Supplementary Files}

This is a list of supplementary files associated with this preprint. Click to download.

- SupplementaryTableS2.pdf

- SupplementaryTables2.pdf

- SupplementaryTableS2.pdf

- Supplementaryinformation.doc

- Supplementaryinformation.doc

- Supplementaryinformation.doc 